Assuntos Internacionais 


\section{A crise do sistema internacional: um futuro pior do que o passado?}

RUBENS RICUPERO

A

SEgunda metade deste título não me pertence. Peguei-a num debate organizado pelo jornal Le Monde no decurso do mês de agosto de 1996. A idéia provinha, por sua vez, de um artigo do editorialista americano William Pfaff, publicado primeiro no World Political Journal, depois traduzido por Commentaire, no 74, durante o verão de 1996. Nesse artigo foi levantada a seguinte questão: "E se não houvesse nenhuma razão de pensar que o futuro será melhor do que o presente ou, pior ainda, melhor do que o passado?"

Não era uma afirmação categórica, mas uma interrogação que escondia uma insinuação pessimista. Isso bastou então ao diário para lançar um debate com o título provocador: "O progresso, uma idéia morta?” O convite à discussão trazia no bojo outra pergunta: "Deve-se desistir de acreditar na idéia de progresso, essa idéia que, de Bacon a Condorcet, animou sucessivamente o pensamento da Renascença e da filosofia das Luzes antes de inspirar, ao mesmo tempo, aos séculos XIX e XX, o liberalismo e o marxismo?”

A redação justificava a reabertura da questão por uma dupla constatação: a da falência do "socialismo real", mas também a dos impasses do capitalismo liberal. De um lado, o perecimento da utopia socialista, mesmo sob a forma democrática, não soviética; do outro, as conseqüências negativas da globalização das economias. Os termos de referência tinham um caráter nitidamente político e não era por acaso que a discussão acontecia no dia seguinte ao das greves do outono de 1995, consideradas na França como a primeira grande onda de manifestações contra a globalização.

Como se esse tema já não fosse de uma ambição quase inatingível, o artigo introdutório ousava ampliar-lhe perigosamente a análise com a evocação de questões ainda mais complexas que são as da bioética e da ecologia. Efetivamente, as respostas, por volta de umas doze, ultrapassaram amplamente os limites do assunto, tendo como resultado inevitável tornar mais superficiais as análises e as conclusões. Primeiro, misturaram-se progresso moral e progresso material, problemas de justiça, de liberdade e de igualdade com os da prosperidade, do desemprego, dos desastres provocados pela tecnologia como Tchernobil, a "vaca louca". Em seguida, quase se perdeu de vista o eixo central original, a saber, o do desaparecimento de uma alternativa fidedigna de organização social da economia e, com ela, da tensão dialética criativa entre socialismo e liberalismo capitalista que animava a esperança de progresso social. 
Assim, fracassou uma discussão que ainda fica por levar avante, a qual constitui um dos problemas básicos do nosso tempo. Não possuo nem a força, nem a competência para iniciá-la e, se evoco hoje o debate de 1996, é apenas para integrar melhor o assunto de que trato no interior do quadro mais amplo a que pertence: a perda da fé na idéia de progresso, herdada da filosofia das Luzes. Basta, com efeito, lembrar aqui o maior espírito dessa época, Immanuel Kant e o seu Projeto filosófico sobre a paz perpétua para compreender-lhe o significado. A concepção de progresso nos séculos XVIII e XIX continha uma pluralidade de dimensões: progresso da ciência, da técnica, da indústria e da economia em geral, assim como da educação e das leis, a suavização dos costumes e das penas, a abolição das superstições e dos preconceitos, sendo o desfecho final, a chave de abóbada dessa construção a paz perpétua, a eliminação da lei da guerra, relíquia dos tempos bárbaros que ameaçava de maneira permanente todas as outras modalidades de progresso.

É curioso notar que, no decorrer do debate, essa dimensão só tinha recebido uma atenção secundária, com exceção da revolução causada pela limpeza étnica na Bósnia e pelo genocídio em Ruanda. Outras questões, tais como as catástrofes ecológicas ou a insegurança econômica, tinham ocupado mais espaço do que a preocupação ligada ao sistema internacional. Aliás, nenhuma menção tinha sido formulada em relação aos perigos que iam logo preocupar os governos, como o terrorismo internacional, a radicalização do fundamentalismo islâmico, os ataques preventivos para evitar a proliferação de certos tipos de armamentos.

O que não impede que, em 1996, há oito anos apenas, se tivesse a impressão de que o sistema internacional se movia na direção certa. Para os leitores, teria sido inconcebível que o seu presente fosse considerado pior do que o seu passado imediato - a era da Guerra Fria e do equilíbrio do terror - ou, ainda mais, pior do que o seu passado distante - o de Auschwitz, de Hiroshima e da Segunda Guerra Mundial. O jornal talvez tivesse escolhido mal o momento; era provavelmente imaturo debater isso. Mas cabe a nós, hoje, levantar a questão. Com efeito, o que parecia, em 1996, um presente em geral positivo, com apenas alguns primeiros sinais de complicações futuras, tornou-se para nós um passado incontestavelmente superior ao nosso presente, um presente inaugurado pelos atentados de setembro de 2001 e continuado pela invasão do Afeganistão, do Iraque, as exações de Guantânamo, de Abu Ghraib, o massacre de mulheres e crianças em Beslan.

Poderiam fazer-me observar que atentados e invasões, massacres e exações aconteciam também em número excessivo durante o período anterior. Qual é então a diferença? O que justifica a percepção de que o nosso presente seria pior do que o nosso passado próximo?

A resposta é que essas duas fases diferem profundamente em sua dinâmica e em sua natureza mesma. Nosso passado imediato corresponde ao período após 
a Guerra Fria. Começa simbolicamente com a queda do muro de Berlim, em outubro de 1989 - data aceita por todos, a começar por Eric Hobsbawm, que a escolheu como fechamento de seu breve século XX. Mais ou menos doze anos mais tarde, ele termina com os atentados de 11 de setembro de 2001. É curto, mas é igualmente de uma fecundidade extraordinária em matéria de soluções trazidas a problemas intratáveis que pareciam destinados a uma longa duração. Sua mais cativante imagem - a demolição do Muro por um povo - harmoniza-se maravilhosamente com o seu conteúdo histórico concreto: a abolição das muralhas físicas ou político-jurídicas entre os povos, a supressão das divisões ideológicas, a destruição das fronteiras de arame farpado e da Cortina de Ferro. Em pouco tempo, vira-se a página do desmembramento de Berlim, da Alemanha, da Europa, do planeta em duas metades antagônicas, fenômeno anunciado pelo comissário do Povo, Maxim Litvinoff, na Conferência de Gênova de 1922, primeira conferência internacional esperada pelo governo revolucionário: "Não há um só mundo mas dois, o dos soviets e o do capitalismo".

Esse verdadeiro degelo, bem melhor do que o posterior à morte de Stalin, terá um efeito de contágio positivo sobre numerosos conflitos ideológicos que encontram solução num lapso de tempo de alguns anos apenas. Consegue-se até resolver uma questão maior que aparentemente não tinha nada a ver com a Guerra Fira, a saber, o apartheid na África do Sul. Note-se, de passagem, que, de novo, há aqui a demolição de um muro político e jurídico e a criação de um país reunificado sob as cores do arco-íris.

É preciso buscar bem longe no passado para encontrar uma taxa comparável de densidade histórica, isto é, de concentração de acontecimentos e de mudanças de tamanha importância por unidade de tempo. E o mais notável ainda é que se trata, em geral, de mudanças para melhor, não para pior; mudanças para resolver e não para criar novos problemas. E isso se efetuou, quase sempre, com um mínimo de violência ou sem violência, salvo algumas exceções como a decomposição da Federação da Iugoslávia. Se se pensar na impiedosa guerra civil de que nascera a União Soviética, na repressão sistemática que caracterizava a dominação soviética na Europa Central e na Europa do Leste, na imposição brutal da segregação do apartheid, o desfecho feliz de todos esses casos citados, aquilo que parecia destinado à tragédia mostra-se quase como um milagre histórico, uma vitória da razão, uma confirmação da boa fundamentação da confiança que tinham os filósofos das Luzes num progresso gradual por evolução e não por revolução.

É nisso que reside, justamente, a diferença radical entre esse passado próximo e nosso sombrio presente. Durante esses efêmeros doze anos, tinha-se acreditado na possibilidade de construir um sistema internacional mais fiel à Carta das Nações Unidas, principalmente ao princípio da segurança coletiva na obediência do Estado de direito tal como está encarnado na Carta. A guerra não seria senão a ultima ratio, o recurso extremo previsto na Carta e aprovado pelo Con- 
selho de Segurança. Uma autêntica "comunidade de segurança" nasceria progressivamente, no interior da qual as contendas seriam resolvidas de maneira pacífica, segundo normas jurídicas e com uma crescente institucionalização, até o momento em que a própria hipótese do conflito armado se tornasse inconcebível. Seria o cumprimento final de esforços de séculos inteiros, a fim de substituir "o estado de natureza" por um "estado de direito" internacional e estabelecer uma autoridade com o monopólio do uso legítimo dos meios de coerção em escala planetária.

Infelizmente, tudo isso reveste hoje o aspecto de uma incorrigível ingenuidade. É necessário, todavia, se perguntar se é preciso imputar toda a responsabilidade da reviravolta unicamente à reação aos atentados terroristas do dia 11 de setembro ou se já existia, nessa fase de inocência, uma diversidade negligenciada que tornaria inelutáveis os dissabores futuros. Aqueles que haviam acreditado então no fim da história não se davam conta de que se estava atravessando um desses instantes históricos fugidios e raros, em que tudo parece convergir porque se acaba de recuperar a homogeneidade perdida. O sistema internacional é homogêneo quando todos os seus membros partilham um só critério de legitimidade e adotam uma organização similar ou compatível em matéria de ordem econômica, social e política. Era o caso do Ancien Régime ${ }^{1}$, com o princípio dinástico como critério de legitimidade e a monarquia absoluta, os privilégios, a economia pré-industrial, como bases da ordem ou da desordem estabelecidas. À semelhança da Revolução Francesa em relação ao Antigo Regime, a Revolução de Outubro tinha igualmente destruído a homogeneidade liberal-burguesa da Belle Époque ${ }^{2}$, introduzindo critérios de legitimidade e de organização radicalmente incompatíveis com os que prevaleciam noutras partes da Europa e mesmo além, no resto do mundo ocidental, os quais não se esgotaram senão com a morte do comunismo e a desintegração de sua vanguarda, a União Soviética.

O desaparecimento ou o enfraquecimento, de maneira definitiva ou temporária, da causa maior da heterogeneidade, torna evidentemente mais fácil a reconstrução da ordem, favorecendo a convergência e o consenso. É natural que, depois dos sofrimentos da heterogeneidade, a redescoberta da homogeneidade seja acompanhada da doce ilusão de restaurar um mundo desaparecido. No momento da derrota de Napoleão e do fim de 22 anos de guerra, compreende-se que, em Viena, Metternich sonhe com $A$ World Restaured, título do livro de Kissinger. Com a mesma fonte de inspiração, Telleyrand tem saudade da "doçura de viver" (para quem?) de antes da Revolução. Outros cultivam a "grande ilusão" de acreditar que a Guerra de 1914 seria a "guerra para acabar com todas as guerras": os burgueses vão se iludir com a volta ao tempo em que tudo não seria senão "ordem e beleza, luxo, calma e volúpia".

No decorrer dos dois últimos séculos e antes da queda do Muro de Berlim, contavam-se três desses episódios de reconstrução da ordem perdida: o Congresso de Viena (1814-1815), depois das guerras de Revolução e do Império; a 
Conferência de Paris (1919), depois da primeira Guerra Mundial; e Bretton Woods (1944) e San Francisco (1945), no fim da Segunda Guerra Mundial. Todos esses episódios tiveram lugar depois de uma conflagração geral que tinha arrastado a totalidade dos atores de um sistema, europeu no primeiro caso, mundial nos dois outros. Em segundo lugar, essas guerras deixavam em ruínas as instituições anteriores, obrigando a sua substituição por novas. Em terceiro lugar, essa substituição havia sido feita pelo viés de negociações, no âmbito de congressos diplomáticos organizados para esse fim e com projetos de acordo escritos. Finalmente, todas essas instâncias, sem exceção, tinham desembocado, para além dos ajustamentos de litígios de fronteiras e de outra natureza, na criação de um processo inédito de caráter político, a saber, de um fórum de discussão e mecanismo de tomada de decisões. O Concerto europeu, a Sociedade das Nações, a Organização das Nações Unidas marcam as etapas sucessivas dos esforços progressivos, imperfeitos mas sempre renovados, colocados em jogo para aperfeiçoar o nível de organização, no âmbito de um mecanismo de caráter universal e de democratização do poder decisório.

O caráter representativo e a legitimidade de cada encarnação nova da organização internacional dependem da combinação desses critérios. Com o fim da descolonização formal e a universalização completa da ONU, o critério decisivo de legitimidade está ligado principalmente ao seu grau democrático, ao seu conteúdo de consenso, de consentimento, de participação, no sentido da noção de hegemonia de Gramsci. Trata-se, com efeito, do poder não somente de vencer, mas de convencer, da capacidade de coagir se necessário, mas principalmente do dom de inspirar, de encarnar ou de interpretar valores simbólicos que dão um sentido às aspirações coletivas, numa palavra, um poder capaz de exercer simultaneamente a liderança político-estratégica e a liderança cultural e moral.

Ora, é justamente em relação a esse critério crucial que o nosso presente se afasta mais dramaticamente do passado de 1945 e do de 1989. A reconstrução da ordem política e econômica no fim da Segunda Guerra é inteiramente devida ao papel hegemônico dos Estados Unidos, país que representava, em vasta medida, os valores e as aspirações da humanidade não submetida ao totalitarismo. Uma vez desencadeada a Guerra Fria, os mecanismos decisórios da ONU ver-se-iam paralisados pela clivagem que se tinha então cavado entre os dois blocos hegemônicos desse novo período da história contemporânea. Ora, no início, a Guerra Fria não impedira o que Dean Acheson chamou um pouco pretensiosamente de "a Criação" no seu livro de memórias Present at the Creation.

O fato é que, deixando de lado Stalin e seus súditos, os outros se reconheciam com facilidade nos ideais de Franklin Delano Roosevelt para a reorganização do mundo e nos de sua mulher, Eleanor, no que concernia os direitos do homem. Esse casal patrício da aristocracia política e cultural do Atlântico norteamericano era o símbolo vivo de uma extraordinária geração de homens de Estado e de intelectuais de que faziam parte pessoas de escol como Marshall, Georges 
Kennan, Galbraith e outros mais. Tinham vivido e sobrevivido à Grande Depressão, tinham salvado o capitalismo americano com o New Deal, conjunto de receitas de intervenção do Estado e de medidas sociais que se pareciam muito com as aspirações de pleno emprego, de welfare wtate do labour inglês, do capitalismo renano, dos europeus dessa época em geral.

Esses homens eram internacionalistas convictos. Pearl Harbor tinha desmoralizado o velho isolacionismo americano. A necessidade incontornável de aliados para conduzir a guerra, primeiro contra o Eixo, depois a que foi batizada de fria, os tinha feito promover a aliança permanente com a Otan, os pactos militares regionais, os mecanismos multilaterais da ONU, instituições tais como Bretton Woods e o Gatt. Tinham tomado cuidado, Roosevelt primeiro, mas principalmente Truman, de garantir para si o apoio bipartidário no Congresso, a fim de evitar o fracasso de Wilson a respeito da Sociedade das Nações. Esse apoio revelou-se indispensável quando os republicanos conquistaram o Senado, onde o formidável senador Arthur H. Vandenberg ia garantir, à testa da poderosa Comissão das Relações Exteriores, o caráter bipartidário da diplomacia, continuada no decurso do reinado de Eisenhower.

Evoquei longamente esse passado perfeito, doravante terminado, porque a descrição pormenorizada do tempo revoluto bastaria, por si só, para sugerir como estamos hoje afastados dele. Acaso será necessário demonstrar que Bush filho, Cheney, Rumsfeld, Condoleezza Rice, Wolfowitz nada têm a ver com a geração dos fundadores da $\mathrm{ONU}$, com os quais não partilham de modo algum nem os valores nem as convicções? A verdade é que há mais de trinta anos, em reação ao último sobressalto do progressismo americano - a great society, a campanha, por vezes violenta, a favor dos direitos civis, a revolução dos costumes de 1968 - os Estados Unidos começam a pender para a direita. Ajudada pelo incremento demográfico e econômico do bible belt do sul e do sudoeste, às expensas do velho norte industrial e cosmopolita, reforçada pela afirmação neoliberal de Reagan, que reduz os impostos e exacerba a concorrência em detrimento dos fracos, essa deriva conservadora encontrará logo uma base política sólida e durável. A ação corajosa do governo do presidente Johnson para impor - pelo viés da intervenção federal - a dessegregação, com o reconhecimento e o respeito dos direitos dos negros, vai manifestar-se para o seu partido como um suicídio político no sul, suicídio glorioso por certo, mas suicídio mesmo assim. O Partido Democrata tornou-se minoritário, de maneira quase permanente, no Congresso, nos executivos e nas assembléias dos Estados. A recente derrota de Kerry acabou de confirmar que a única possibilidade, para esse partido, de chegar de novo à presidência é fazê-lo com candidatos sulistas mais à direita, como Jimmy Carter (Geórgia) ou Bill Clinton (Arkansas).

A deriva conservadora não é um acidente eleitoral, mas um fenômeno cultural e de sociedade. É por isso que a chegada ao poder de Bush-II, longe de ser uma anomalia e a causa dessa deriva, não representa senão o desfecho do proces- 
so e a sua conseqüência lógica. Pode-se identificar por toda parte sinais dessa transformação: num Judiciário cada vez mais tradicionalista, no declínio dos sindicatos, na influência crescente da direita religiosa em política, na evolução conformista de uma imprensa outrora independente e crítica, na posição defensiva em que foram acuadas as forças outrora ofensivas que reclamavam a extensão da proteção do meio ambiente, dos direitos das mulheres, dos índios, das minorias sexuais.

Já faz muito tempo, bem antes de Bush-II, que essa tendência não poupa a ONU. Depois da Guerra da Coréia, e à medida que das maiorias nas Nações Unidas se recusam a ver através do prisma da Guerra Fria problemas mais complexos como a Guerra do Vietnã, o apartheid ou as guerras de libertação da África, os americanos começam então a se desencantar da ONU. Embaixadores de extrema agressividade, como Jeanne Kirkpatrick, vão colocar em moda a derisão sistemática da organização, a UN bashing. Aumenta o fosso entre a maioria da Assembléia Geral e os Estados Unidos a propósito de Israel e das conseqüências das guerras no Oriente Médio. A resolução anti-sionista leva ao paroxismo esse sentimento de rejeição da ONU pelos americanos. Washington não hesita mais em encarar a sua retirada, permanente ou temporária, das organizações que lhe tenham desagradado, tais como o BIT, a Unesco, a Onundi. Surge um fenômeno inquietante: torna-se cada vez mais difícil associar os Estados Unidos ao que se estaria tentado de chamar o work in progress, a ampliação do que se adquiriu no passado e a sua extensão a espaços novos conducente a um consenso universal em via de formação. Vimo-lo primeiro com o insucesso da tentativa de obter a plena adesão de Washington ao novo Direito do Mar, insucesso que se repetiu em seguida com o direito ao desenvolvimento, as novas gerações dos direitos sociais, econômicos, culturais, com numerosas convenções do BIT, com a promessa de dedicar $0,7 \%$ do PIB ao desenvolvimento, culminando essa não-adesão com os problemas colocados pela assinatura, depois a ratificação da Convenção relativa aos direitos da criança, a recusa do tratado sobre as minas antipessoal, o tratado que estabelece a Corte Penal Internacional, que foi assinado, depois a seguir unsigned, quer dizer, em que a assinatura foi anulada! Quanto ao meio ambiente, se os americanos finalmente aderiram à Convenção das Nações Unidas sobre as mudanças climáticas, continuam recusando a convenção sobre a biodiversidade, apesar dor retoques que lhe foram feitos, ao mesmo tempo em que, depois de ter aceitado o Protocolo de Kyoto, mudaram de opinião e procuram por todos os meios destruí-lo, assim como fazem com a Corte Penal.

A essa atitude de negativismo em relação ao consenso internacional emergente, acrescenta-se o abandono ou a re-interpretação de uma parte do que já foi universalmente adquirido, principalmente em matéria de direitos humanos, do meio ambiente, das experiências com mísseis, dos compromissos assumidos no passado para com os países que renunciaram às armas nucleares e, de maneira geral, em oposição aos esforços multilaterais de desarmamento, mesmo no caso 
das armas de pequeno calibre (small arms). Quando se consideram, por outro lado, os esforços vigorosos que empenham contra a proliferação das armas de destruição em massa, sem se impor em contrapartida a si mesmos nenhuma obrigação, mesmo longínqua ou meramente retórica, de proibição total dessas mesmas armas - objetivo que, entretanto, sempre fizera parte de todos os esforços de não-proliferação - então só se pode colocar em dúvida a coerência e a eficácia persuasiva de sua política.

Essa enumeração não é absolutamente exaustiva - poder-se-ia acrescentar a derrubada unilateral por Nixon dos pilares de Bretton Woods, fundamento da ordem econômica do após-guerra, ou as medidas comerciais unilaterais - mas a enumeração basta para prometer duas conclusões. A primeira é que os problemas vêm de longe, foram, por certo, enormemente agravados pelo atual governo, mas não desaparecerão por milagre logo que, à imagem de Stephen no Ulisses de Joyce, tivermos conseguido despertar do pesadelo da História provocado por Osama ben Laden e Bush. A segunda é que não se vê bem como se poderia pensar em reformar em profundidade a ONU para construir uma futura ordem internacional melhor do que a do presente e do passado, no momento em que o único país capaz de desempenhar um papel hegemônico construtivo, exacerba o seu "excepcionalismo" e prefere acentuar o que o separa dos outros, ao invés de reforçar o que o une ao resto do mundo e o faz partilhar o destino comum.

É nisso que reside o dilema a que deve fazer frente o sistema internacional articulado em torno das Nações Unidas. De uma parte, criado pelos Estados Unidos, esse sistema não tem possibilidade alguma de renovar-se, nem mesmo talvez de sobreviver, sem o engajamento decisivo e proativo de seu fundador e membro principal. De outra, a potência hegemônica não parece capaz de reunir a maioria das opiniões públicas e dos governos mundiais em torno de um projeto reformador da ONU.

É tempo agora de voltar atrás, à passagem em que tínhamos indicado quais eram as características e as condições dos momentos excepcionais da História que fizeram nascer um mundo novo. Percebe-se sem esforço que essas condições não estão absolutamente presentes hoje. Não houve uma conflagração geral que gerasse um desmantelamento irremediável das instituições políticas e econômicas do mundo antigo. A desintegração da URSS e do "socialismo real" não pode de forma alguma ser comparada a tal fenômeno, pois que não destruiu nem o Conselho de Segurança, nem as organizações Bretton Woods, nem a OMC, à qual a China aderiu e a Rússia se prepara para fazê-lo. Nesse caso concreto, a amplitude das mudanças políticas e territoriais foi a de um tremor de terra cujo poder destrutivo se limitou unicamente aos regimes e países concernidos, o que se parece mais com o retorno da França de Talleyrand ao Concerto das grandes potências européias reunidas no Congresso de Viena do que com o esmagamento definitivo e à parte da Alemanha nazista em 1945. A luta contra o terrorismo internacional, que domina as relações internacionais desde setembro de 2001 e é 
por vezes comparada com exagero à Guerra Fria, não derrubou tampouco o Conselho de Segurança e a Carta, ainda que os tenha minado, nem chegou a seu termo com a vitória de um campo e o afastamento ou o desaparecimento do outro, criando as condições propícias à reconstrução.

Não tendo saído arrasadas dos acontecimentos de 1989 ou de 2001 a 2003, as instituições existentes não fizeram sentir a necessidade da apresentação de projetos escritos e formais para substituí-las. Exceto no caso da relação do comitê dos sábios nomeado por Kofi Annan, sobre a oportunidade da qual sempre emiti reservas e que não visa, em todo caso, senão a uma reforma limitada, preferiu-se deixar a coisa correr. Bush pai tinha falado muito, entretanto, de uma "nova ordem internacional" e depois, com o malogro da operação na Somália, subitamente parou. Se por vezes se tem a impressão de que nada aconteceu, é talvez por causa dessa ausência de um processo formal seguido, com regulamentos prévios escritos, tais como as Atas do Congresso de Viena, os tratados de paz, de fronteiras e outros, estabelecidos no fim das duas guerras mundiais. Não se percebeu que o processo já existia, que produzia resultados extraordinários - as transmissões mais ou menos de veludo na URSS e nos países comunistas ou a abolição do apartheid - e que uma ordem nova, com um mapa-múndi inteiramente transformado, não somente em suas fronteiras, mas também em suas instituições políticas, econômicas, culturais, estavam em vias de vir a lume. Mas o processo, ainda inacabado, se parece daí por diante com o método progressivo, informal, ad hoc, caso por caso, piecemeal, como na Constituição inglesa e não com um processo cartesiano com um projeto debatido e redigido por sábios, como na Constituição da União Européia. Com todas as falhas reconhecidas, o sistema internacional atual passou com sucesso por uma das provas mais difíceis para qualquer sistema, a de acomodar e de encaminhar as forças da mudança, de permitir a transformação sem ser destruída por ela.

Se o sistema obteve maior ou menor sucesso, e a prova é que a maioria lhe é apegada, então por que esse mal-estar, essa sensação de crise, essa iniciativa do próprio secretário geral de instituir um comitê para "salvá-lo"? Isso se deve essencialmente à percepção de que o sistema fracassou em certas crises de alcance excepcional, seja pelos valores morais em jogo, seja pelas graves conseqüências a longo prazo. Esses casos, pouco numerosos, são, em última análise, em número de três: o genocídio de Ruanda, a limpeza étnica na Bósnia, seguida da paralisia do Conselho de Segurança no Kosovo e, finalmente, a invasão do Iraque sem o aval do Conselho de Segurança. No outro extremo, esquece-se facilmente de que o sistema da ONU chegou a resultados notáveis em situações de extrema delicadeza, como na Namíbia, no Cambodja e no Timor Leste. Não obstante, é inegável que as três derrotas do sistema não podem ser postas de lado sem que se reaja ao desafio que elas carregam para a frente do palco, o das "novas ameaças": o genocídio ou a violação maciça dos direitos humanos pelos governantes, o terrorismo internacional protegido por estados "gatunos" e a disseminação de armas de destruição em massa pela ação desse gênero de Estados e/ ou por terroristas. 
Os três insucessos mencionados são extremamente sérios, mas é preciso perguntar-se se devem ser colocados na conta das carências e dos erros eventuais da Carta e de seus mecanismos - isto é, um problema legal e institucional - ou se têm origem nos desacordos sobre o julgamento a propósito de uma situação perigosa concreta e nos meios de lhes levar remédio. Na primeira hipótese, o remédio clássico, o da reforma institucional, estaria na ordem do dia. No segundo caso de figura, isto é, se a dificuldade reside em fatos concretos e na falta de consenso a seu respeito, a reforma será antes um escopo, uma fuga para frente, uma manifestação renovada da ilusão de encontrar nas mudanças das instituições a chave de soluções que se encontram noutra parte.

Se o problema central se encontrasse na Carta, então seria preciso regulamentar o direito de veto, cujo uso ou ameaça desempenhou um papel capital em cada um dos três casos examinados. Quem ignora, entretanto, que o veto é uma espécie de "defeito de fabricação" original, desejado pelos poderosos como a própria condição da existência da ONU. É possível encarar uma reforma realista qualquer que fosse capaz de contornar a recusa obstinada, ameaçadora e fatal de Clinton, causa maior da negação de socorro a Ruanda, ou o veto russo e as hesitações européias, motivo principal da agravação da tragédia iugoslava?

Finalmente, no caso dos atentados terroristas, seria falso acusar a ONU ou a comunidade internacional de ter faltado ao dever de solidariedade. Muito ao contrário, o sobressalto de simpatia e de sustentação foi unânime e se exprimiu de maneira eficaz na coordenação das medidas para evitar o desmoronamento das bolsas, partilhar as informações e harmonizar a luta antiterrorista, até a aprovação pelo Conselho de Segurança de todas as resoluções indispensáveis, incluindo a operação contra o governo dos talibãs. O desacordo com Washington só toma corpo depois do funesto discurso sobre o eixo do mal e as infelizes alusões à idéia de cruzada. Um passo decisivo é dado em seguida com o discurso do verão de 2002, em West Point, onde Bush afirma que as doutrinas da Guerra Fria (o represamento e a dissuasão) são doravante ineficazes contra "as redes terroristas que agem na sombra" e contra "ditadores desequilibrados munidos de armas de destruição em massa e tendo a capacidade de promover ataques de mísseis com tais armas ou de entregá-las secretamente a terroristas aliados".

O lançamento oficial da doutrina do ataque preventivo (preemptive attack) alargou o fosso que separava os EUA da maioria dos outros países até torná-lo quase intransponível. Viu-se, em seguida, que nada, nem os esforços dos inspetores da ONU, nem a boa vontade do Conselho de Segurança iria parar a primeira aplicação dessa doutrina contra o Iraque. Verificou-se que essa primeira experiência desmoralizou a doutrina, pois que demonstraram-se falsas todas as suas suposições. Será possível, então, dizer, como fez um jornalista inglês, que "a guerra do Iraque foi a guerra preventiva para acabar com todas as guerras preventivas", ou aplicar a esse conflito as palavras do general Omar Bradley a respeito da louca idéia de MacArthur de lançar uma guerra atômica contra a China em 1951: "a guerra errada, no momento errado, no lugar errado, contra o inimigo errado". 
A recapitulação dos passos que levaram ao desfecho iraquiano esclarece à saciedade que se tratava aqui de uma divergência irredutível, não sobre a lei, mas sobre o diagnóstico e a terapia do problema colocado por Saddam Hussein, desembocando na questão de saber se ele justificava o recurso a um ataque preventivo. À luz desse precedente, será conveniente integrar o ataque preventivo no sistema de direito da Carta? A resposta do grupo dos dezoito especialistas convocados pelo governo suíço foi negativa por unanimidade: "Não há nenhuma necessidade de mudar o sistema de segurança coletiva por causa dos novos perigos... Toda tentativa de interpretar o artigo $5 \mathrm{l}$ (da Carta) de maneira extensiva poderia colocar em perigo a interdição do recurso à força”. O comitê dos sábios chegou, quanto ao essencial, à mesma conclusão enumerando as condições clássicas para o ouso da força, condições que, aliás, não se encontravam no caso do Iraque.

No fundo, existe uma incompatibilidade irredutível entre a segurança coletiva e o ataque preventivo, dois caminhos opostos para buscar a segurança, a ação cooperativa, no primeiro caso, a ação unilateral, il sacro egoismo, como se diria em italiano, no segundo. Para os estrategistas do Pentágono, o direito de autodefesa pelo ataque preventivo é quase sinônimo de arbítrio. Como o poder absoluto, ele não sofre nenhum limite e tolera mal as regras ou as prorrogações devidas à deliberação multilateral. Levado ao extremo, é o equivalente do estado de exceção e justifica o que dizia Walter Benjamin na oitava das Teses sobre o conceito de história: "A tradição dos oprimidos nos ensina que o estado de exceção em que vivemos é a regra".

Eis-nos chegados ao núcleo do desacordo atual sobre o sistema internacional. Nenhum sinal de abrandamento desponta no horizonte; nem as mudanças no âmbito do Gabinete americano, nem a campanha feroz contra Kofi Annan e a ONU, nem os rumores de uma operação contra o Irã autorizam sonhar com amanhãs que cantem.

A dissensão e a divergência estão de volta e polarizam, como foi visto no decorrer das recentes eleições, pelos americanos e pelo mundo. A nova heterogeneidade cobre toda uma vasta gama cromática que vai do cinza mais ou menos intenso, no seio da aliança atlântica, até o preto mais sombrio entre os antípodas, os que se autodenominam neoconservadores do governo de Washington e os fundamentalistas de Al Qaida.

Nessa atmosfera de esquartejamento crescente, nada é mais insensato do que a idéia de substituir a ONU por uma organização das democracias, idéia lançada pela extrema direita americana. Primeiro, essa espécie de Otan ampliada não seria mais eficiente do que a sua congênere militar de Bruxelas, um instrumento em busca de uma causa. Acreditar em outra coisa seria ignorar a evidência de que o que criou o impasse sobre o Iraque no Conselho de Segurança não foi a divergência entre os Estados Unidos em relação ao Chile ou em relação ao Gabão, mas o desacordo dos americanos em relação com a França, a Alemanha e 
a esmagadora maioria das opiniões públicas ocidentais, até no Reino Unido, na Espanha ou na Itália. Por outro lado, uma organização das democracias ricas, um clube dos abastados, seria, em termos de idéia de progresso herdado das Luzes, a mesma coisa que fazer a História avançar para trás, levando-a de volta aos bons tempos dos tzares e da Santa Aliança.

O símbolo visual da heterogeneidade reencontrada é não mais a demolição, mas a reedificação dos muros. Eles podem ser físicos, como o muro de separação entre israelenses e palestinos, ou o da fronteira entre os Estados Unidas da América e o México; por vezes, são político-jurídicos, como os campos de internação para candidatos ao asilo ou as muralhas policiais erigidas para afastar "os condenados da Terra", que se afogam à vista da terra prometida européia; perto de nós, existem fortificações de aço e de arame farpado isolando as embaixadas e os locais de reuniões econômicas internacionais. A variedade dos muros é quase infinita, mas um ponto lhes é comum a todos: eles separam os seres humanos, são construídos para dividir, raiz da palavra diabolos, aquele que traz a divisão.

Há um pequeno texto de que gosto muito, pronunciado por ocasião de uma entrevista em La Stampa por Emmanuel Levinas, um pouco antes de sua morte. Cito-o com freqüência, pois exprime maravilhosamente o nosso desconforto atual. Perguntaram a Levinas se ele achava que o fim do comunismo era uma grande vitória para a democracia. Ele respondeu:

Não, penso que as democracias perderam e muito. Apesar de todos os seus horrores, os seus excessos, o comunismo representara sempre uma esperança e uma expectativa de uma ordem social mais eqüitativa. Não é que os comunistas tivessem uma solução, ou que preparassem uma. Ao contrário. Existia, entretanto, a idéia de que a História tinha um sentido, uma direção e que viver não era insensato, absurdo. Tratava-se de uma idéia de que as pessoas tinham no Ocidente desde o século XVIII e que, graças a Marx, tinha adquirido raízes profundas no século XX. Não acredito que o fato de ter perdido essa idéia para sempre seja uma grande conquista espiritual. Até ontem acreditávamos saber aonde ia a História e que valor devíamos dar ao tempo. Agora, caminhamos sem finalidade, perguntando-nos a cada instante: "Que horas são?" De modo fatalista, um pouco como se faz o tempo todo na Rússia "Que horas são?" "Ninguém sabe".

É um texto rico e pungente, no sentido do dicionário, de algo que nos rasga o coração. Deixo-o para a sua reflexão, acrescentando apenas que o coração, Levinas o tinha do lado certo. Sabia que o que dá sentido à História e a nossa vida pessoal é o esforço para reparar o malefício feito aos fracos e para construir, não muros, mas uma ordem social eqüitativa. A melhor herança das Luzes não é uma idéia qualquer do progresso, mas de um progresso com conteúdo moral e humano. Gian Battista Vico, o grande napolitano, nos ensinara que a História é inteligível porque é feita por homens para os homens. A História, a sociedade em marcha, terá o sentido que lhe tivermos dado por nossa ação. 
É preciso, para isso, que o consenso indispensável à ação seja baseado numa solidariedade tão indivisível quanto a paz. Solidariedade contra os terroristas que massacram inocentes, mas solidariedade igualmente com os oprimidos, as vítimas da ocupação estrangeira, dos estupros, das torturas, do genocídio, da aids, da mudança climática. É por aí que passa o caminho rumo à reconstrução da homogeneidade perdida. O futuro não é absolutamente predeterminado por nosso difícil presente. Devemos enfrentá-lo com a esperança da bela frase de Walter Benjamin utilizada por Marcuse à guisa de conclusão de $O$ homem unidimensional: "É somente por causa daqueles que são sem esperança que a esperança nos é dada”.

\section{Notas}

l Sistema monárquico absoluto na França (Nota do tradutor).

2 Literalmente "Bela Época", fase de euforia vivida na Europa, particularmente na França, entre 1871, final da guerra franco-prussiana, e 1914, início da Primeira Guerra Mundial, caracterizada por grande produção artística e desenvolvimento tecnológico (Nota do tradutor).

Palavras-chave: Assuntos Internacionais, Sistema Internacional, Globalização.

Keywords: Foreign Affairs, International System, Globalization.

Rubens Ricupero faz parte do Institut Universitaire de Hautes Études Internationales (HEI) (Instituto Universitário de Altos Estudos Internacionais), e é membro do Conselho Editorial desta revista.

Tradução de Mario Laranjeira. O original em francês - La crise du système international: un avenir pire que le passé? - encontra-se à disposição do leitor no IEA-USP para eventual consulta.

Texto recebido em 17 de janeiro de 2005 e aceito para publicação em 26 de janeiro de 2005 . 